\title{
Characterization of dissolved organic matter from surface waters with low to high dissolved organic carbon and the related disinfection byproduct formation potential
}

\author{
Angzhen $\mathrm{Li}^{\mathrm{a}}{ }^{\mathrm{b}}$, Xu Zhao ${ }^{\mathrm{a}, *}$, Ran Mao ${ }^{\mathrm{a}}$, Huijuan Liu ${ }^{\mathrm{a}}$, Jiuhui $\mathrm{Qu}^{\mathrm{a}}$ \\ a State key Laboratory of Environmental Aquatic Chemistry, Research Center for Eco-Environmental Sciences, Chinese Academy of Sciences, Beijing 100085, \\ China \\ ${ }^{\mathrm{b}}$ China Academy of Urban Planning and Design, Beijing 100044, China
}

\section{H I G H L I G H T S}

- The DBPFP of source waters did not correlate with the DOC value.

- SUVA didn't represent the potential to form DBP in low-aromatic waters.

- The Hi fraction played an important role in DBPFP for waters.

- Phenolic hydroxyl group tended to form TCM and TCAA during chlorination.

- Carboxyl and alcoholic hydroxyl groups tended to form DCAA and Br-DBP.

\section{G R A P H I C A L A B S T R A C T}

The characterization of DBP precursors from three source waters in China revealed that the DBPFP did not correlate with the DOC value. The Ho fraction mainly contained phenolic hydroxyl and conjugated double bonds which were reactive with chlorine to produce DBP, especially TCM and TCAA. The Hi fraction may contain more amino, carboxyl and alcoholic hydroxyl groups, which had the great potential to form DCAA and Br-DBP during chlorination.

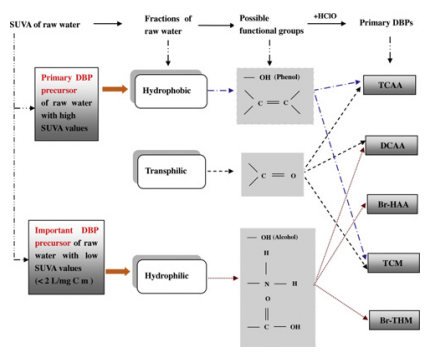

\begin{abstract}
A B S T R A C T
In this study, the disinfection byproduct formation potential (DBPFP) of three surface waters with the dissolved organic carbon (DOC) content of $2.5,5.2$, and $7.9 \mathrm{mg} / \mathrm{L}$ was investigated. The formation and distribution of trihalomethanes and haloacetic acids were evaluated. Samples collected from three surface waters in China were fractionated based on molecular weight and hydrophobicity. The raw water containing more hydrophobic (Ho) fraction exhibited higher formation potentials of haloacetic acid and trihalomethane. The DBPFP of the surface waters did not correlate with the DOC value. The values of DBPFP per DOC were correlated with the specific ultraviolet absorbance (SUVA) for Ho and Hi fractions. The obtained results suggested that SUVA cannot reveal the ability of reactive sites to form disinfection byproducts for waters with few aromatic structures. Combined with the analysis of FTIR and nuclear magnetic resonance spectra of the raw waters and the corresponding fractions, it was concluded that the Ho fraction with phenolic hydroxyl and conjugated double bonds was responsible for the production of trichloromethanes and trichloroacetic acids. The Hi fraction with amino and carboxyl groups had the potential to form dichloroacetic acids and chlorinated trihalomethanes.
\end{abstract}

(c) 2014 Published by Elsevier B.V.

\footnotetext{
* Corresponding author. Tel.: +8610 62849160; fax: +86 1062849160 .

E-mail addresses: liangzhen403@sina.com (A. Li), zhaoxu@rcees.ac.cn (X. Zhao), jdmrr@163.com (R. Mao), hjliu@rcees.ac.cn (H. Liu), jhqu@rcees.ac.cn (J. Qu).
} 


\section{Introduction}

It is recognized that dissolved organic matter (DOM) is the principal precursor of disinfection byproducts (DBPs) in the chlorination treatment $[1,2]$. Trihalomethanes (THMs) and haloacetic acids (HAAs) are the two major groups of DBPs, which are potentially carcinogenic $[3,4]$. Therefore, it is important to understand the relationship between the characteristics of DOM and DBPs yields.

To understand the composition of DOM in surface water, DOM has been isolated and fractionated by ultrafiltration and resin fractionation according to the molecular weight and physicochemical properties [5-9]. The hydrophobic fraction with large molecular weight DOM was found to be the most important source of DBPs precursors $[8,10]$. Hydrophilic fraction may also contribute substantially to the formation of DBPs especially in waters with low humic component [11]. Moreover, it was found that the characteristics of natural organic matter (NOM) in surface water depended on climate, geological conditions and surrounding watersheds [12-14]. Although some studies were performed to characterize NOM in several source waters $[12,14,15]$, little information was focused on the composition and characteristics of DBPs precursors in different regions of China, especially for the individual structure of DBPs precursors in waters with high concentration of bromide.

A different formation trend of THMs and HAAs in the chlorination treatment was reported $[3,16]$. The presence of bromide in DOM also had an effect on the formation and distribution of THMs and HAAs during the chlorination process [8,17]. Several researchers have tried to correlate water quality parameters, such as dissolved organic carbon (DOC) and specific ultraviolet absorbance divided by dissolved organic carbon (SUVA) to disinfection byproduct formation potential (DBPFP) of DOM $[3,10,18]$. SUVA has been found to be a good indicator for quantifying NOM reactivity in DBPs formation [3,7]. By contrast, Ates et al. reported that SUVA did not correlate well with the formation and species of DBPs in waters with low DOC content [11]. Thus, it was required that an integrated analytical approach to elucidate the chemical composition and physical structures of DBPs precursors.

The primary aim of this research was to compare the characteristics of DBPs precursors from three water sources in China containing low to high DOC levels. The effectiveness of SUVA value in predicting DBPs formation with different bromide, SUVA and DOC levels was investigated. The raw waters and the corresponding fractions were examined for their associated functional groups by three dimensional excitation-emission matrix (3DEEM) fluorescence, fourier transform infrared (FT-IR) and ${ }^{13} \mathrm{C}$ nuclear magnetic resonance $\left({ }^{13} \mathrm{C}\right.$ NMR) spectra analysis. Relationship between the structures of DBPs precursors and DBPs species was explored.

\section{Materials and methods}

\subsection{Raw water sampling}

The raw waters were collected from three potable water sources between October 2011 and July 2012. The water sources were as follows: Miyun Reservoir (Beijing (BJ), northern China), Weishan Lake (Xuzhou (XZ), east China), and Hongze Lake (Lianyungang (LYG), east China). Samples were collected in $25 \mathrm{~L}$ plastic bottles and delivered to the laboratory. After being filtrated by a pre-rinsed $0.45 \mu \mathrm{m}$ glass fiber filters, the samples were stored in the dark at $4{ }^{\circ} \mathrm{C}$.

\subsection{Resin and membrane separation of the DOC fractions}

NOM was fractionated into five fractions using a stirred ultrafiltration cell device (Model 8200, Amicon, Millipore) with nominal molecular weight cutoffs of $3,10,30$, and $100 \mathrm{kDa}$ regenerated cellulose membranes (PL, $63.5 \mathrm{~mm}$, Millipore). Experiments followed the procedure described by Kitis et al. (2002). Meanwhile, NOM was also fractionated by resin fractionation. The filtered NOM was acidified to $\mathrm{pH} 2$ using $6 \mathrm{M}$ sulfuric acid and then passed through DAX-8 resin followed by XAD-4 resin, in accordance with the method of Aiken et al. (1992). Effluent from the XAD-4 resin was collected and named as the hydrophilic (Hi) fraction. The hydrophobic (Ho) and transphilic (Hs) fractions were retained by DAX-8 and XAD4 resin (Supelco, Bellefonte, PA, USA) respectively. These fractions were eluted with $0.1 \mathrm{M}$ sodium hydroxide in the reverse direction. The Ho and Hs fractions were concentrated again on the MSC-H cation exchange resin obtained from $\mathrm{J} \& \mathrm{~K}$ in order to remove the salt of the Ho and Hs fractions. Each NOM fraction was diluted to original state with ultrapure water and the $\mathrm{pH}$ value was adjusted to be $7.0 \pm 0.2$ using $\mathrm{H}_{2} \mathrm{SO}_{4}$ or $\mathrm{NaOH}$. The DOC concentration and the UV absorbance at $254 \mathrm{~nm}\left(\mathrm{UV}_{254}\right)$ of each NOM fraction were measured.

\subsection{DBPs formation potential}

Chlorination experiment was carried out according to the Standard Method 5710 with modifications [19]. As described in the "Standard Method 5710B", the reaction time for THMFP should be 7 days. However, it is also described in 5710D that "for some compounds, such as brominated haloacetic acids, are not stable and can degrade during storage-either during a long reaction time, 7 days may be too long for some compounds". The NaOCl stock solution $\left(20 \mathrm{mg} / \mathrm{mL}\right.$ as $\left.\mathrm{Cl}_{2}\right)$ was stored in aluminum foil-covered glass stopped flask. Chlorine dosing solution was prepared from the dilution of $\mathrm{NaOCl}$ stock solution (about $5 \mathrm{mg} / \mathrm{mL}$ as $\mathrm{Cl}_{2}$ ). $\mathrm{NaOH} / \mathrm{KH}_{2} \mathrm{PO}_{4}$ buffer solutions ( $\mathrm{pH} 7.0$ ) and chlorine dosing solution were injected into each sample. The chlorine dose was determined by $4 \mathrm{~h}$ preliminary demand tests on each sample according to Standard Method 5710B [19]. After being dosed with chlorine, samples were stored at $25 \pm 2{ }^{\circ} \mathrm{C}$ in the dark for $24 \mathrm{~h}$. Free chlorine residuals of the samples were measured by an $\mathrm{N}, \mathrm{N}$-diethyl-p-phenylenediamine (DPD) titrimetric method [20]. After the addition of the sodium sulfite into the water samples, the concentrations of trihalomethanes formation potential (THMFP) and haloacetic acids formation potential (HAAFP) were determined according to the procedure [21].

Four THMs $\left(\mathrm{CHCl}_{3}, \mathrm{CHBrCl}_{2}, \mathrm{CHBr}_{2} \mathrm{Cl}, \mathrm{CHBr}_{3}\right)$ species were extracted with hexane (HPLC Grade, Fisher, USA) and measured according to the U.S EPA Method 551 [22]. Nine HAAs (monochloro-, monobromo-, dichloro-, bromochloro-, dibromo-, bromodichloro-, bromodichloro-, dibromochloro-, trichloro- and tribromoacetic acid) samples were extracted with methyl-tertbutyl ether (MTBE) (HPLC Grade, J.T. Baker, USA) followed by being derivatized with acidic methanol according to the US EPA method 552.3 [22]. 1, 2-dibromopropane ( $\geq 98.0 \%$, GC, Fluka, USA) was served as the interval standard. Quantitative analysis was conducted using a gas chromatograph (6890 N, Agilent) with an electron capture detector (ECD). The experiment conditions were given in the supporting information.

\subsection{Characterization of DBPs precursors}

The samples of DBPs precursors obtained through a freezedrying treatment were analyzed for their structural and chemical characteristics. KBr (FT-IR Grade, Aldrich Co., USA) was mixed with the powder of DBPs precursors and the FT-IR spectra of the mixture were obtained with an IR spectrometer (Thermo Nicolet 5700, USA).

3DEEM fluorescence spectra were recorded on a fluorescence spectrophotometer (model F-4500, Hitachi, Japan). 3DEEM spectra were obtained by measuring the emission spectra ranging from 
280 to $550 \mathrm{~nm}$ repeatedly at the excitation wavelengths from 220 to $440 \mathrm{~nm}$. Blank samples of ultra-pure water were included in the correction of inner filtering and Raman scattering of the fluorescence spectra.

The solid-state ${ }^{13} \mathrm{C}$ NMR spectra were acquired using a cross polarization magic angle spinning (CPMAS) on a Bruker instrument (AVANCE III, $400 \mathrm{MHz}$, Bruker, Germany) with a $4 \mathrm{~mm} \mathrm{H} / \mathrm{X} / Y$ probe. ${ }^{13} \mathrm{C}$ CPMAS NMR was performed on $100-200 \mathrm{mg}$ of the samples (contact time of $3 \mathrm{~ms}$, pulse delay of $1 \mathrm{~s}$, spinning rate of $5000 \mathrm{~Hz}$ and 20480 scans).

The $\mathrm{pH}$ values of these water samples were measured by a pH meter (720 A, Thermo Orion, USA). Dissolved organic carbon (DOC) was measured by a TOC analyzer (Shimadzu, TOC-VCPH total organic carbon analyzer, Japan). The water samples were filtered by the membrane ( $0.45 \mu \mathrm{m}$ Millipore Co., USA). UV was measured by a spectrophotometer (Hitachi, U-3010 spectrophotometer, Japan). Bromide concentrations were measured using measured using ion chromatograph (IC, ICS-2000, Dionex, Sunnyvale, CA) equipped with an IonPac AS-19 anion column and an IonPac AG19 guard column.

\section{Results and discussion}

\subsection{Fractionation analysis of $B J, L Y G$ and $X Z$ raw waters}

The tested surface waters (BJ, LYG and XZ raw waters) were collected from the drinking water sources with low to high DOC values in China. The raw waters were fractionated by ultrafiltration and resin fractionation according to the molecular weight and
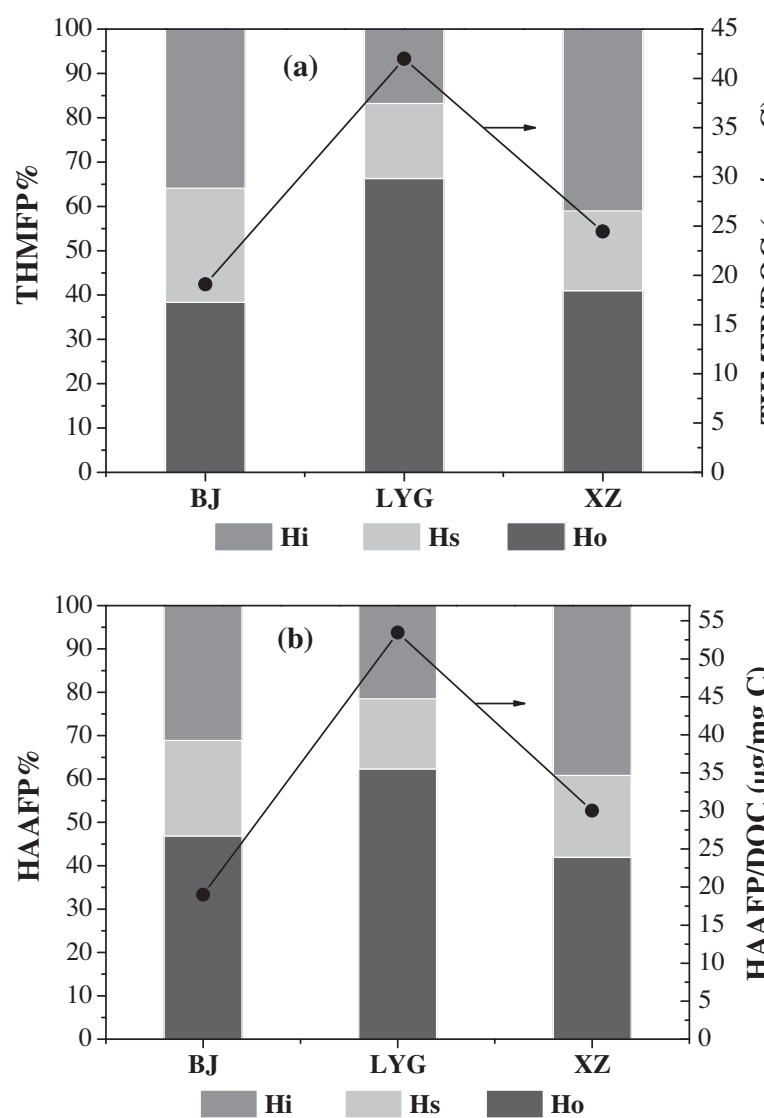

physicochemical properties. As shown in Table S1 Table S1, DOC of the raw waters follows the order: $X Z>L Y G>B J$. SUVA values differ from DOC values with the following rank order: $L Y G>X Z>B J$. Among them, $\mathrm{XZ}$ raw water shows the highest bromide concentration. Moreover, the Ho fraction is the most abundant of the DAX partition-based groups. It is shown in Table S1 that the percent content of the hydrophobic carbon increases with the increase of the SUVA value. With the decrease of the SUVA levels, the percentage of $\mathrm{Hs}$ and $\mathrm{Hi}$ fractions increases, indicating that Hi fraction becomes an important fraction for the low SUVA waters. There also exists a trend that the fraction with large molecular size has relatively high level of SUVA. Similar results were also reported by Ates et al., who observed that the natural waters with SUVA values $<2 \mathrm{~L} / \mathrm{mg} \mathrm{DOC}^{-1}$ contained mostly hydrophilic, non-humic and small molecular weight NOM fractions [11]. The strong correlation between SUVA and the aromatic-carbon content of NOM in the natural waters has also been reported by others $[7,15]$.

\subsection{DBPFP of BJ, LYG and XZ raw waters and the corresponding fractions}

The DBPFP of BJ, LYG, XZ raw waters and corresponding fractions were measured to assess the reactivity of each water source with chlorine. Fig. 1(a) and (b) illustrates the DBPFP distribution of the three resin fractions of the raw waters. The highest value of THMFP/DOC ( $41.98 \mu \mathrm{g} / \mathrm{mg} \mathrm{C})$ and HAAFP/DOC ( $53.43 \mu \mathrm{g} / \mathrm{mg} \mathrm{C})$ yields was observed in the LYG raw water among the three raw waters. Based on the SUVA levels of the water fractions, it is shown that the Ho fractions always gave higher DBPFP than their
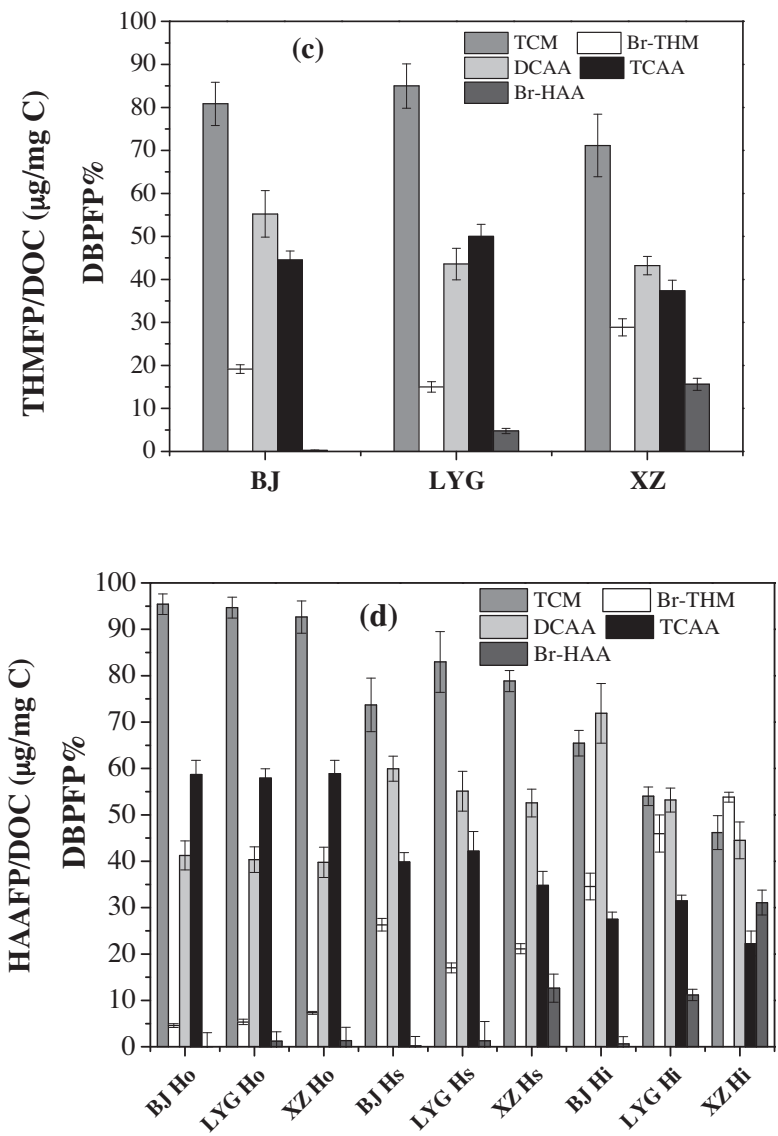

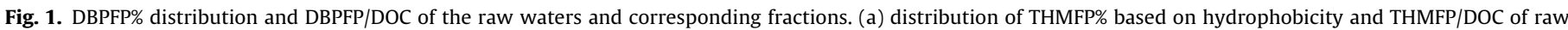

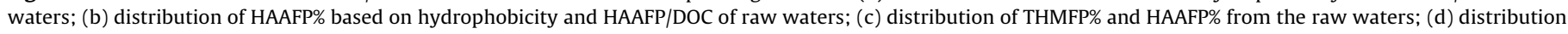
of THMFP\% and HAAFP\% from the corresponding fractions. 

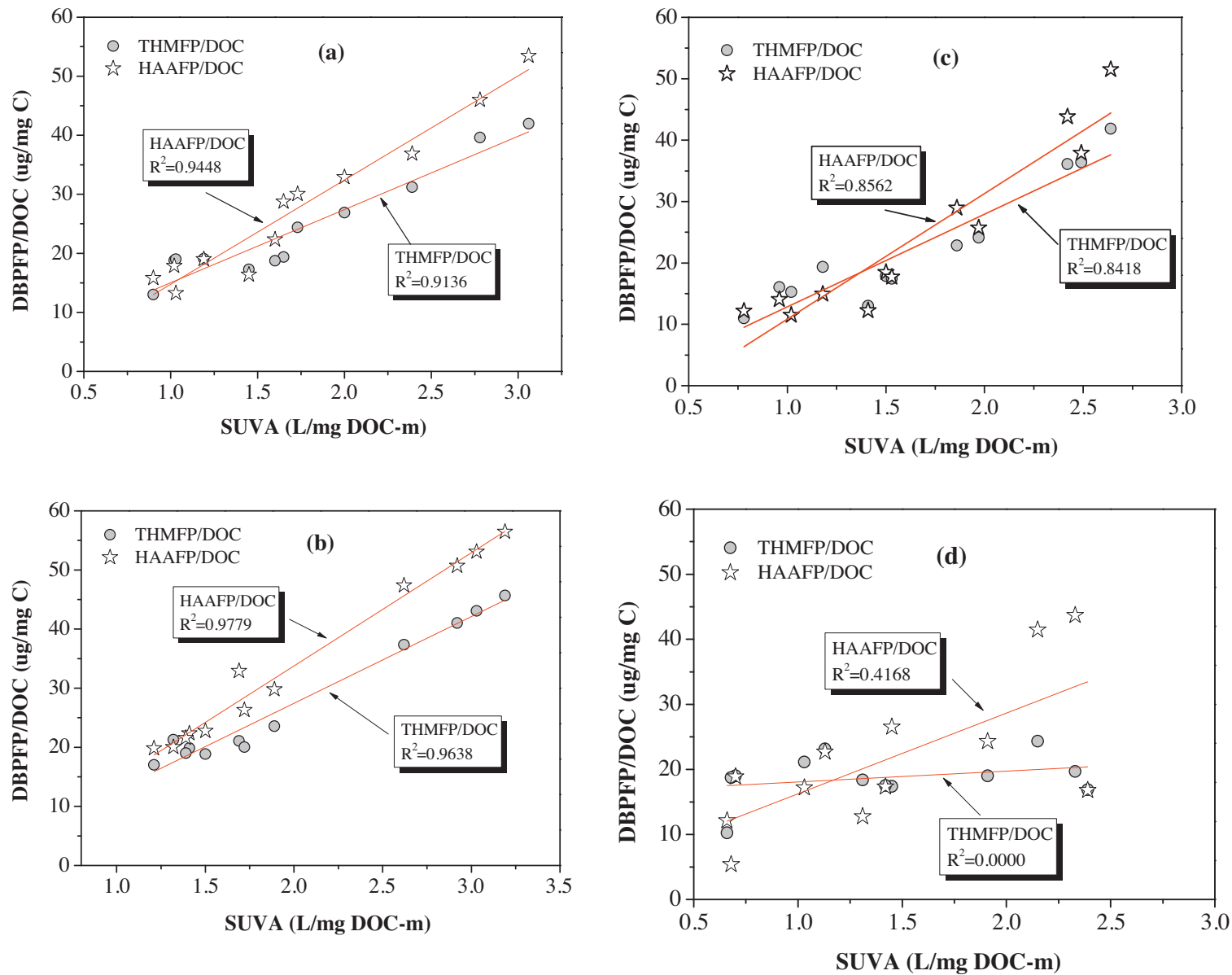

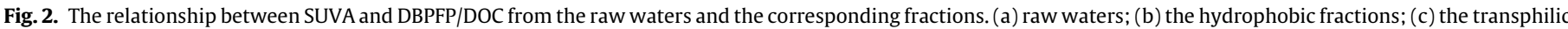
fractions; (d) the hydrophilic fractions.

corresponding $\mathrm{Hs}$ and $\mathrm{Hi}$ fractions, but hydrophilic carbon also plays an important role in the disinfection byproduct formation for the water samples with SUVA values $<2 \mathrm{~L} / \mathrm{mg} \mathrm{DOC}^{-1}$.

Fig. 1(c) and (d) indicate that the distribution of brominated trihalomethane (Br-THM), trichloromethane (TCM), dichloroacetic acid (DCAA), trichloroacetic acid (TCAA) and brominated haloacetic acids (Br-HAA) from the three raw waters and corresponding resin fractions during the chlorination. As shown in Fig. 1(c), the LYG raw water produces the most amounts of TCM (84.98\%) and TCAA (50\%) among them. While XZ raw water exhibits the highest levels of Br-THM (28.86\%) and Br-HAA (15.64\%) than BJ and LYG raw waters. This result indicated that the densities of TCAA are higher than DCAA in high-SUVA waters.

It was interesting to find that TCM and TCAA were the major DBPs species in the Ho fractions. The Hs and Hi fractions produced higher levels of Br-THM, Br-HAA and DCAA in THMFP and HAAFP than Ho fraction. Especially, the Hi fractions of LYG and XZ raw waters exhibited the densities of Br-THM up to $45.98 \%$ and $48.64 \%$, respectively. This result indicates bromine is more reactive with the $\mathrm{Hi}$ fraction than with the corresponding Ho and Hs fraction in the formation of THMs and HAAs. Liang et al. reported that dihaloacetic acid $\left(X_{2} A A\right)$ precursors were not as hydrophobic as the trihaloacetic acid $\left(X_{3} A A\right)$ precursors [3]. This result suggests that TCM and TCAA precursors are more hydrophobic, while the Hi fractions are important as $\mathrm{Br}$-THM, Br-HAA and DCAA precursors. These results verified the hypothesis proposed by Heller-Grossman that chlorination was preferred by aromatic precursors, while bromination was preferred by aliphatic structures [23].

\subsection{The relationship between SUVA and DBPFP/DOC}

It is shown in Fig. 2 that the correlationship between SUVA values and DBPFP/DOC in BJ, LYG, XZ raw waters and fractions. These raw waters were collected on October, December, April and July from 2010 to 2011. It is observed a strong correlation between SUVA and DBPFP/DOC for the three raw waters and corresponding Ho fractions. Especially, the linear correlation coefficients $\left(R^{2}\right)$ for THMFP/DOC and HAAFP/DOC achieve 0.96 and 0.98 for Ho fractions, respectively. On the other hand, the correlation coefficients were relatively low for Hs fractions. The DBPFP/DOC of the Hi fractions shows a weak relation with their corresponding SUVA values.

These results were in accordance with the previous studies, in which strong correlations were observed between DBPs formations and SUVA values for a total of five source waters [24]. However, a contrary result was reported that there were no significant correlations between SUVA and THMFP/DOC of some NOM fractions $[8,11]$. These different trends suggest that the effectiveness of SUVA in correlation with the DBPs formation depends on the characteristics of NOM. Tran et al. reported that the Ho fraction generally contained a large proportion of aromatic structures [25]. However, the Hi fraction contained many aliphatic carbon and nitrogenous compounds [26]. Thus, SUVA appeared to be a better indicator for the reactivity of the compounds that comprise aquatic humic substances than for the DOC present in the whole water samples. SUVA does not represent the reactive sites on NOM moieties, which were responsible for DBPFP in low-aromatic waters. Combined with the above results, it was concluded that those small molecular weight 


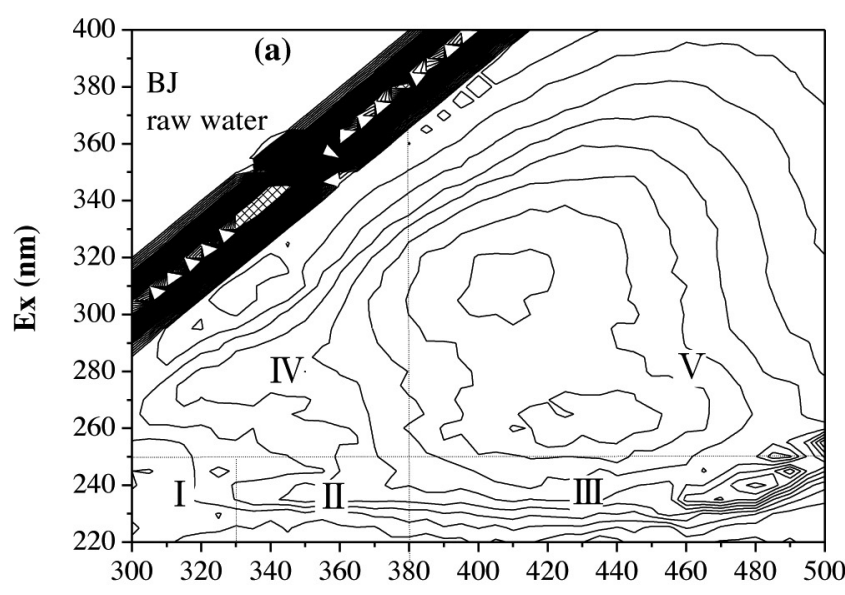

Em (nm)

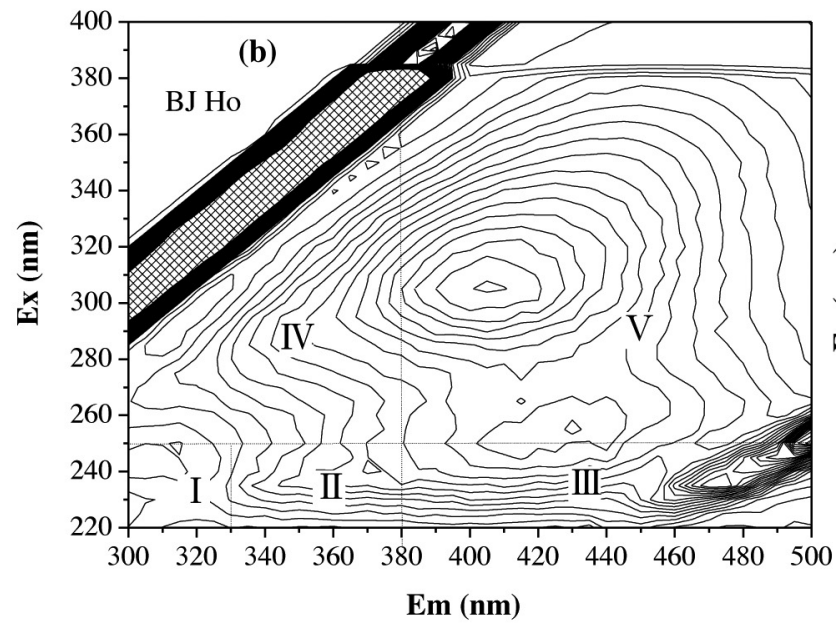

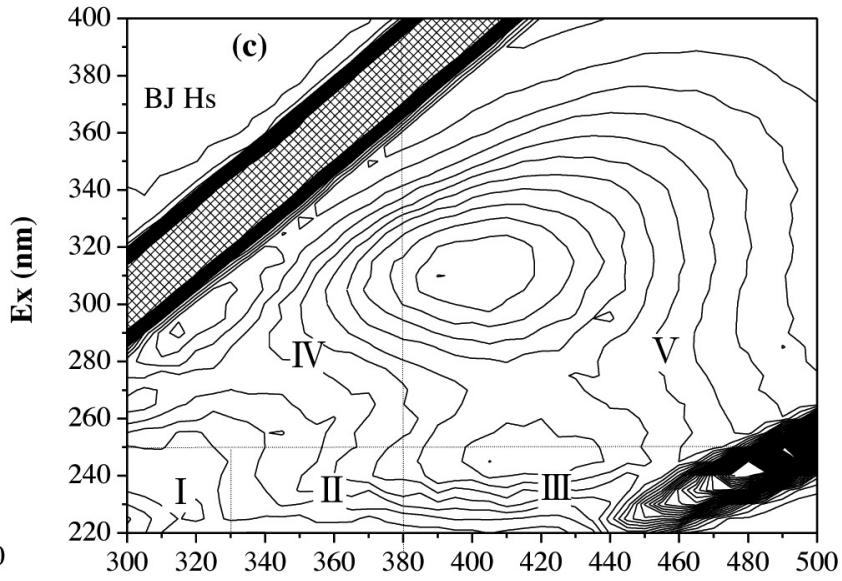

Em (nm)

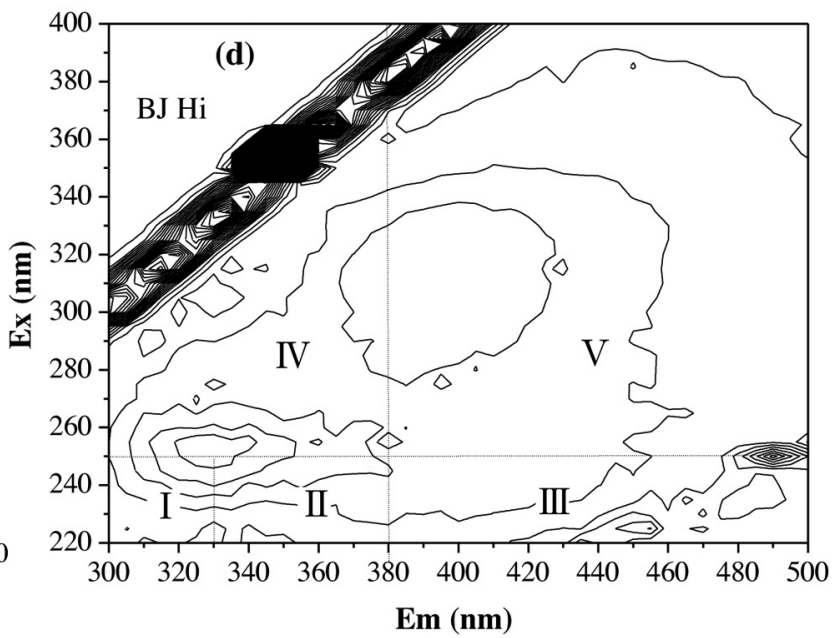

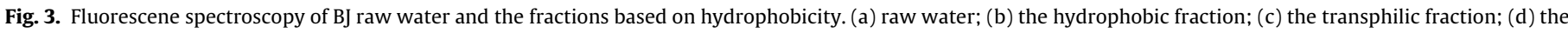
hydrophilic fraction.

and hydrophilic charged fractions may play important roles in DBPs formations with low SUVA values.

\subsection{Structural characteristics of BJ, LYG, XZ raw waters and corresponding fractions}

\subsubsection{DEEM fluorescence spectroscopy analysis}

Detailed 3DEEM illumination for BJ, LYG, XZ raw waters and corresponding fractions is shown in Fig. 3, Fig. S1, Fig. S2 and Table S2. Using consistent excitation and emission wavelength boundaries, the 3DEEM was divided into five regions based on the results by Chen et al. [27]. They also reported that fluorescence regional integration (FRI) analysis was developed to characterize DOM in water using quantitative technique. Normalized excitation-emission area volumes $\left(\Phi_{i, n}, \Phi_{T, n}\right)$ and percent fluorescence response $\left(P_{i, n}\right)$ was deduced by Chen et al. [27].

$\Phi_{i, n}=\mathrm{MF}_{i} \sum_{\mathrm{ex}} \sum_{\mathrm{em}} \mathrm{I}\left(\lambda_{\mathrm{ex}} \lambda_{\mathrm{em}}\right) \Delta \lambda_{\mathrm{ex}} \Delta \lambda_{\mathrm{em}}$

$\Phi_{T, n}=\sum_{i=1}^{5} \Phi_{i, n}$

$P_{i, n}=\frac{\Phi_{i, n}}{\Phi_{T, n}} \times 100 \%$

where $\mathrm{MF}_{i}$ is a multiplication factor for each region, $\Delta \lambda_{\mathrm{ex}}$ is the excitation wavelength interval (taken as $5 \mathrm{~nm}$ ), $\Delta \lambda_{\text {em }}$ is the emission wavelength interval (taken as $5 \mathrm{~nm})$, and $I\left(\lambda_{\mathrm{ex}}, \lambda_{\mathrm{em}}\right)$ is the fluorescence intensity at each excitation-emission wavelength pair. The FRI results of BJ, LYG, XZ raw waters and corresponding fractions were presented in the Supporting information (Table S3). It can be calculated that BJ and LYG raw waters were dominated by fluorescence in Region $\mathrm{V}$, and relevant $P_{5, \mathrm{n}}$ values were $33 \%$ and $52 \%$, respectively. However, Region I and Region $V$ were dominated the fluorescence of the $\mathrm{XZ}$ raw water. For the corresponding fractions of the raw waters, it is shown in Fig. 3, Fig. S1, and Fig. S2 that the peak of Ho appears in Region $\mathrm{V}$, and $P_{5, \mathrm{n}}$ values for the Ho fractions of BJ, LYG and XZ waters are $43 \%, 62 \%$ and $34 \%$, respectively. While the peaks of Hs fractions appear in Region III and Region V, the peaks of Hi fractions appear in Region II or Region IV.

It is known that $f_{450 / 500}$ corresponded to the ratio of emission intensity at $450 \mathrm{~nm}$ over $500 \mathrm{~nm}$ at $370 \mathrm{~nm}$ excitation. Some researchers indicated that lower $f_{450 / 500}$ may refer to the compounds with more aromatic structures [28,29]. The $f_{450 / 500}$ for the BJ, LYG and XZ raw waters was 1.78, 1.68 and 1.74, respectively. For the corresponding fractions, it was found that the $f_{450 / 500}$ value of Ho fractions is lower than the $\mathrm{Hs}$ and Hi fractions. Combined with the FTIR analysis, it is concluded that although BJ, LYG and $X Z$ raw waters contain humic acid-like substances, LYG raw water may have more aromatic sites than the others. XZ raw water may also have nitrogen-containing moieties. Moreover, the Hi fraction is assumed to comprise soluble microbial products and proteinlike materials containing amino acids and carbohydrates, whereas the Hs fractions primarily contained fulvic and humic acid-like 


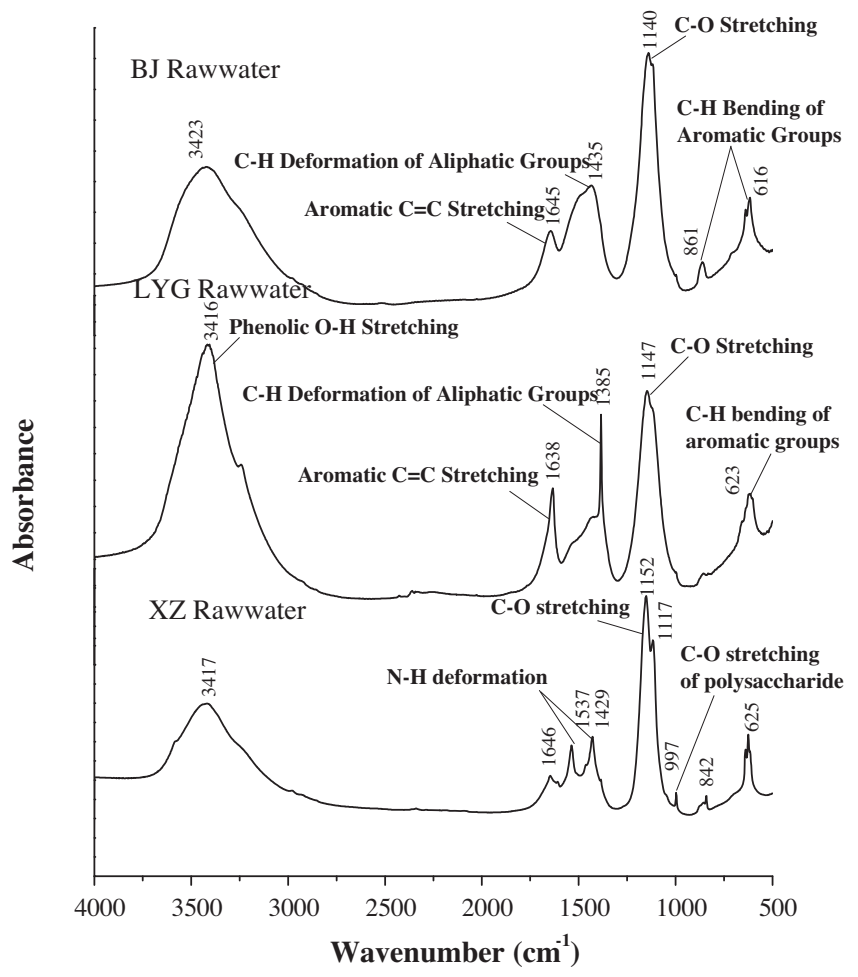

Fig. 4. FT-IR spectra of BJ, LYG and XZ raw waters.

substances; the Ho fractions were in the high degree of $\pi$ bonds (electron-rich) with aromatic structures.

\subsubsection{FT-IR and ${ }^{13} \mathrm{C}$ CPMAS NMR spectroscopy analysis of NOM}

The FT-IR spectra for BJ, LYG, XZ raw waters and their fractions of $\mathrm{Ho}, \mathrm{Hi}$, and $\mathrm{Hs}$ are shown in Fig. 4 and Fig. S3. As seen in Fig. 4, LYG raw water exhibits stronger peak intensity at $1385 \mathrm{~cm}^{-1}$, $1638 \mathrm{~cm}^{-1}$ and $3416 \mathrm{~cm}^{-1}$ than $\mathrm{BJ}$ and XZ raw waters do, which are attributed to $\mathrm{C}-\mathrm{H}$ deformation of aliphatic groups, aromatic $\mathrm{C}=\mathrm{C}$ stretching vibration and $\mathrm{O}-\mathrm{H}$ stretching from the presence of phenols, respectively $[7,10,30]$. Whereas $\mathrm{XZ}$ raw water shows peaks at $997 \mathrm{~cm}^{-1}, 1429 \mathrm{~cm}^{-1}$ and $1537 \mathrm{~cm}^{-1}$, which correspond to $\mathrm{C}-\mathrm{O}$ stretching of polysaccharide and $\mathrm{N}-\mathrm{H}$ deformation [10,31]. These peaks suggest that LYG raw water may contain more aromatic and long aliphatic chain organics than $\mathrm{BJ}$ and $\mathrm{XZ}$ raw waters, while $\mathrm{XZ}$ raw water mainly contain hydrophilic carbohydrates and amino acids, which are in agreement with the 3DEEM results.

It is shown in Fig. S3 that the Ho fractions show peaks at around $1140 \mathrm{~cm}^{-1}$ and $3425 \mathrm{~cm}^{-1}$, which refer to phenolic $\mathrm{C}-\mathrm{O}$ and $\mathrm{O}-\mathrm{H}$ stretching vibration, respectively $[7,31]$. Whereas Hs fractions show a peak at $1718 \mathrm{~cm}^{-1}$, which is attributed to carboxylic and carbonyl $\mathrm{C}=\mathrm{O}$ stretching [10]. Ho and $\mathrm{Hs}$ fractions are similar in spectra with a peak at around $880 \mathrm{~cm}^{-1}$ and $1440 \mathrm{~cm}^{-1}$, which refer to $\mathrm{C}-\mathrm{H}$ bending of the substituted aromatic groups and $\mathrm{C}-\mathrm{H}$ deformation of aliphatic groups, respectively $[30,31]$. In comparison with Ho and Hs fractions, Hi fractions show peaks at around $1008 \mathrm{~cm}^{-1}$ and $1070 \mathrm{~cm}^{-1}$, which are assigned to $\mathrm{C}-\mathrm{O}$ stretching of polysaccharide or polysaccharide-like substances [31]. Hi also shows peaks at $1178 \mathrm{~cm}^{-1}$ and $1286 \mathrm{~cm}^{-1}$, which are attributed to $\mathrm{C}-\mathrm{O}$ stretching and $\mathrm{C}-\mathrm{O}, \mathrm{O}-\mathrm{H}$ bending of carboxylic groups, respectively $[10,30,32]$. Additionally, Hi fractions of LYG and XZ waters show a slight shoulder or a peak at around $1540 \mathrm{~cm}^{-1}$, which correspond to $\mathrm{N}-\mathrm{H}$ deformation and $\mathrm{C}=\mathrm{N}$ stretching of primary amides [10]. Based on the above analysis, it can be concluded that the Ho fraction mainly contained phenolic hydroxyl and conjugated double, whereas the Hs fraction contained more carbonyl than Ho fraction. The Hi fraction may contain more carboxyl, amino and alcoholic hydroxyl groups than Ho and Hs fractions. It was concluded that the Ho fraction with phenolic hydroxyl and conjugated double bonds was responsible for the production of trichloromethanes and trichloroacetic acids. The above conclusion may be supported by some recent reports, in which some aromatic halogenated DBPs are found to be actual intermediate DBPs that can decompose to form commonly known DBPs including HAAs and THMs [33-35].

$\mathrm{BJ}, \mathrm{LYG}$ and $\mathrm{XZ}$ raw waters and fractions of $\mathrm{XZ}$ water were characterized by ${ }^{13} \mathrm{C}$ CPMAS NMR spectrometry in order to obtain additional insights into the organic structural groups. As shown in Fig. 5, XZ raw water exhibits higher content of carbons with resonances in the range of 50-110 ppm than BJ and LYG raw waters. However, LYG raw water showed the highest carbon resonance in the region of 110-160 ppm among the three raw waters.

It was reported that the integrated signal across five chemical shift regions representing the relative intensity of those broad C class: alkyl-C (0-50 ppm), O-alkyl-C (predominantly carbohydrates, 50-110 ppm), aromatic-C (110-160 ppm), carboxyl-C (160-190 ppm), and carbonyl-C (190-220 ppm) [36]. Furthermore, the aromaticity and aliphaticity of the samples were calculated according to Eqs. (4) and (5):

Aromaticity $=\frac{\mathrm{C}_{\delta_{0-110}}}{\mathrm{C}_{\delta_{0-160}}} \times 100 \%$

Aliphaticity $=\frac{\mathrm{C}_{\delta_{0-110}}}{\mathrm{C}_{\delta_{0-160}}} \times 100 \%$

The relative intensity of functional groups for the BJ, LYG and XZ raw waters and fractions of $\mathrm{XZ}$ water by ${ }^{13} \mathrm{C}$ CPMAS NMR spectra are indicated in Table S4. LYG raw water was characterized by the highest aromaticity (38.58\%) among the three raw waters. While XZ raw water comprises the highest content of the carbohydrate and 


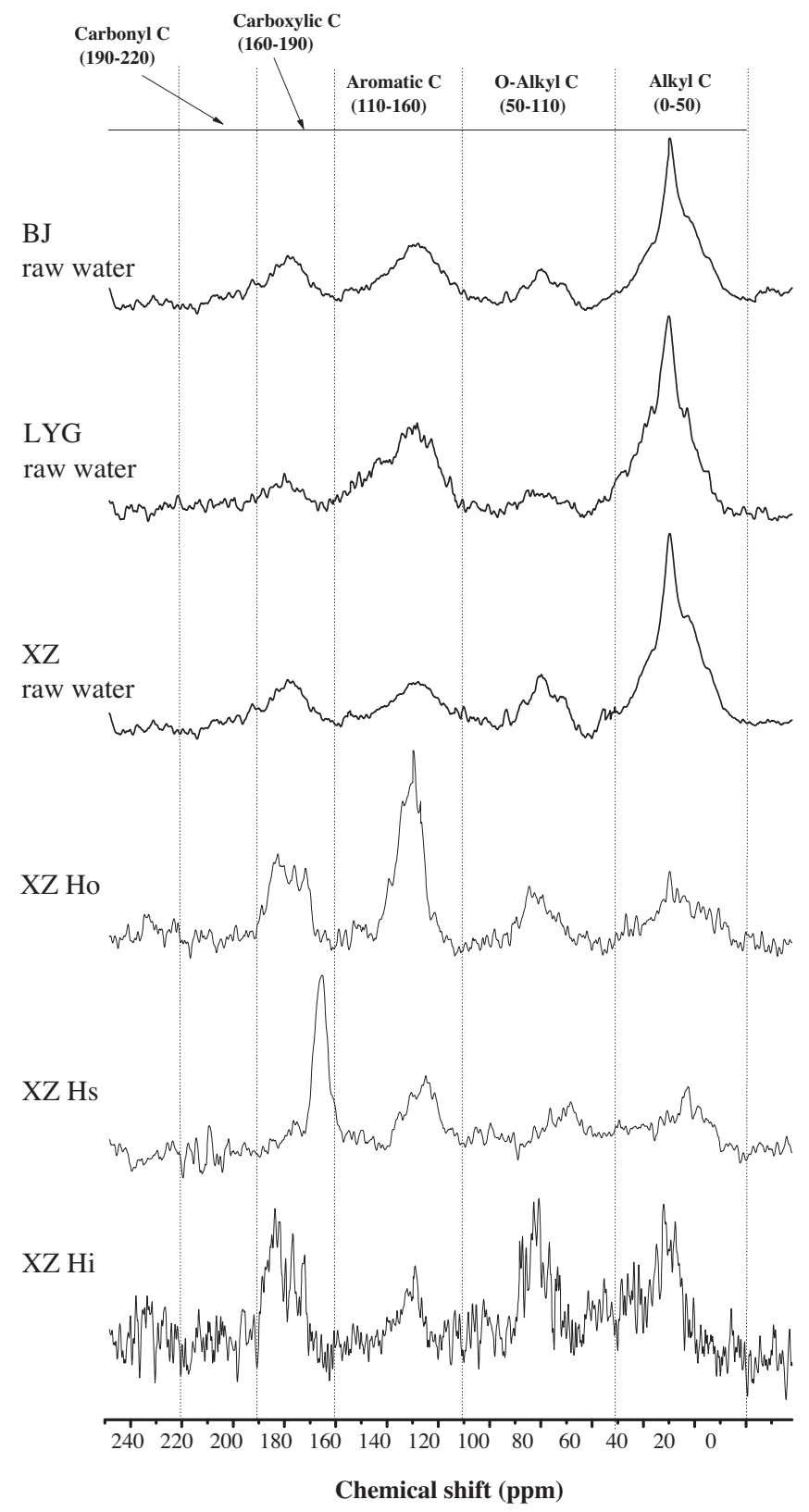

Fig. 5. ${ }^{13} \mathrm{C}$ CPMAS NMR spectra of BJ, LYG, $\mathrm{XZ}$ raw waters and fractions of $\mathrm{XZ}$ waters.

carboxyl group. Moreover, the Ho fractions of $\mathrm{XZ}$ water present more aromaticity (58.14\%) and more intense resonances in aromatic and olefinic unsaturated carbons than $\mathrm{Hs}$ and $\mathrm{Hi}$ fractions. The Hs fractions contain more carbonyl carbon (5.87\%) than the others. However, the relatively strong signals in the region of 50-110 ppm indicate that the $\mathrm{Hi}$ fraction contains more oxygen linked aliphatic alcohols, ethers, esters or polysaccharides than the Ho and Hs fractions. Additionally, the weak shoulder at $52 \mathrm{ppm}$ in the Hi fraction may be due to the $\mathrm{C}-\mathrm{N}$ of amines and amides groups. These results were consistent with the FT-IR analysis.

\section{Conclusions}

Summarily, it was revealed that the potential to form disinfection byproducts did not correlate with the dissolved organic carbon content. The relationship between SUVA and DBPFP/DOC of the raw waters and the corresponding fractions indicated that SUVA did not represent the reactive sites of the NOM moieties, which were responsible for DBPFP in the low-aromatic waters. The hydrophobic fraction mainly contained phenolic hydroxyl and conjugated double bonds, which were primarily responsible for the disinfection byproducts of trichloromethanes and trichloroacetic acids formation during the chlorination. By contrast, the hydrophilic fraction played an important role in the disinfection byproduct formation for the water samples with SUVA values $<2 \mathrm{~L} / \mathrm{mg} \mathrm{DOC}^{-1}$. The hydrophilic fraction may contain more amino and carboxyl groups, which were the main precursors for dichloroacetic acids and chlorinated trihalomethanes.

\section{Acknowledgement}

This work was supported by National Natural Science Foundation of China (No. 51290280; 51225805, 21377148). 


\section{Appendix A. Supplementary data}

Supplementary data associated with this article can be found, in the online version, at http://dx.doi.org/10.1016/ j.jhazmat.2014.02.009.

\section{References}

[1] J. Jacangelo, J. DeMarco, D. Owen, S. Randtke, Selected processes for removing NOM: an overview, J. Am. Water Works Assoc. 87 (1995) 64-77.

[2] O. Gibert, B. Lefevre, M. Fernandez, X. Bernat, M. Paraira, M. Pons, Fractionation and removal of dissolved organic carbon in a full-scale granular activated carbon filter used for drinking water production, Water Res. 47 (2013) 2812-2829.

[3] L. Liang, P.C. Singer, Factors influencing the formation and relative distribution of haloacetic acids and trihalomethanes in drinking water, Environ. Sci. Technol. 37 (2003) 2920-2928.

[4] W.H. Gan, W.H. Guo, J.M. Mo, Y.S. He, Y.J. Liu, W. Liu, Y.M. Liang, X. Yang, The occurrence of disinfection by-products in municipal drinking water in China's pearl river delta and a multipathway cancer risk assessment, Sci. Total Environ. 447 (2013) 108-115.

[5] G.R. Aiken, D.M. Mcknight, K.A. Thorn, E.M. Thurman, Isolation of hydrophilic organic acids from water using nonionic macroporous resins, Org. Geochem. 18 (1992) 567-573.

[6] J.A. Leenheer, J.P. Croue, M. Benjamin, G.V. Korshin, C.J. Hwang, A. Bruchet, G.R Aiken, Comprehensive isolation of natural organic matter from water for specia characterization and reactivity testing, ACS Symp. Ser. 761 (2000) 68-83.

[7] M. Kitis, T. Karanfil, A. Wigton, J.E. Kilduff, Probing reactivity of dissolved organic matter for disinfection byproduct formation using XAD-8 resin adsorption and ultrafiltration fractionation, Water Res. 36 (2002) 3834-3848.

[8] G.H. Hua, D.A. Reckhow, Characterization of disinfection byproduct precursors based on hydrophobicity and molecular size, Environ. Sci. Technol. 41 (2007) 3309-3315.

[9] H.C. Hong, F.Q. Huang, F.Y. Wang, L.X. Ding, H.J. Lin, Y. Liang, Properties of sediment NOM collected from a drinking water reservoir in South China, and its association with THMs and HAAs formation, J. Hydro. 476 (2013) 274-279.

[10] A. Matilainen, E.T. Gjessing, T. Lahtinen, L. Hed, A. Bhatnagar, M. Sillanpaa, An overview of the methods used in the characterization of natural organic matter (NOM) in relation to drinking water treatment, Chemosphere 83 (2011) 1431-1442.

[11] N. Ates, M. Kitis, U. Yetis, Formation of chlorination by-products in waters with low SUVA-correlations with SUVA and differential UV spectroscopy, Water Res. 38 (2007) 4139-4148.

[12] R. Fabris, C.W.K. Chow, M. Drikas, B. Eikebrokk, Comparison of NOM characte in selected Australian and Norwegian drinking waters, Water Res. 42 (2008) 4188-4196

[13] J.Y. Fang, X. Yang, J. Ma, C. Shang, O. Zhao, Characterization of algal organic matter and formation of DBPs from chlor(am)ination, Water Res. 44 (2010) 5897-5906

[14] C. Chen, X.J. Zhang, L.X. Zhu, J. Liu, W.J. He, H.D. Han, Disinfection by-products and their precursors in a water treatment plant in North China: seasonal changes and fraction analysis, Sci. Total Environ. 297 (2008) 140-147.

[15] J.Z. Zhang, W.J. Yu, W. An, J. Liu, Y.J. Wang, Y.J. Chen, J. Tai, M. Yang, Characterization of disinfection byproduct formation potential in 13 source waters in China, J. Environ. Sci. 23 (2011) 183-188.

[16] H.C. Hong, Y.J. Xiong, M.Y. Ruan, F.L. Liao, H.J. lin, Y. Liang, Factors affecting THMs, HAAs and HNMs formation of Jin Lan reservoir water exposed to chlorine and monochloramine, Sci. Total Environ. 444 (2013) 196-204.

[17] C. Tian, R.P. Liu, T.T. Guo, H.J. Liu, Q. Luo, J.H. Qu, Chlorination and chloramination of high-bromide natural water: DBPs species transformation, Sep. Purif. Technol. 102 (2013) 86-93.
[18] P.C. Singer, S.D. Chang, Correlations between trihalomethanes and total organic halides formed during water treatment, J. Am Water Works Assoc. 81 (1989) 61-65.

[19] A.E. Greenberg, L.S. Clesceri, A.D. Eaton, Standard Methods for the Examination of Water and Wastewater, nineteenth ed., American Public Health Association, Washington, DC, 1995.

[20] L.S. Clesceri, A.E. Greenberg, A.D. Eaton, Standard Methods for the Examination of Water and Wastewater, twentieth ed., American Public Health Association, American Water Works Association, Washington, DC, 1998, 461-463.

[21] J. Li, H.J. Liu, X. Zhao, J.H. Qu, R.P. Liu, J. Ru, Effect of preozonation on the characteristic transformation of fulvic acid and its subsequent trichloromethane formation potential: presence or absence of bicarbonate, Chemosphere 71 (2008) 1639-1645

[22] USEPA, Methods for the Determination of Organic Compounds in Drinking Water supplement I, USEPA, Cincinnati, OH, 1990.

[23] L. Heller-Grossman, J. Manka, B. Limoni-Relis, M. Rebhun, Formation and distribution of haloacetic (bromo-chloro) acids in chlorination and bromode-rich lake water, Water Res. 27 (1993) 1323-1331.

[24] M. Kitis, T. Karanfil, J.E. Kilduff, A. Wigton, The reactivity of natural organic matter to disinfection by-products formation and its relation to specific ultraviolet absorbance, Water Sci. Technol. 43 (2001) 9-16.

[25] H. Tran, J. Scott, K. Chiang, R. Amal, Clarifying the role of silver deposits on titania for the photocatalytic mineralization of organic compounds, J. Photochem. Photobiol. A 183 (2006) 41-52.

[26] A.Z. Li, X. Zhao, J.H. Qu, Characteristic transformation of humic acid during photoelectrocatalysis process and its subsequent disinfection byproduct formation potential, Water Res. 45 (2011) 6131-6140.

[27] W. Chen, P. Westerhoff, J.A. Leenheer, K. Booksh, Fluorescence excitationemission matrix regional integration to quantify spectra for dissolved organic matter, Environ. Sci. Technol. 37 (2003) 5701-5710.

[28] J. Swietlika, E. Sikorska, Application of fluorescence spectroscopy in the studies of natural organic matter fractions reactivity with chlorine dioxide and ozone, Water Res. 38 (2004) 3791-3799.

[29] W.T. Li, Z.X. Xu, M.A. Li, W. Wu, Q. Zhou, J.N. Wang, HPLC/HPSEC-FLD with multi-excitation/emission scan for EEM interpretation and dissolved organic matter analysis, Water Res. 47 (2013) 1246-1256.

[30] C.K. Hyun, J.Y. Myong, Characterization of natural organic matter in conventional water treatment processes for selection of treatment processes focused on DBPs control, Water Res. 39 (2005) 4779-4789.

[31] I. Valdemar, O. Marta, C. Armando, Comparative characterization of humic substances from the open ocean, estuarine water and fresh water, Org. Geochem. 40 (2009) 942-950.

[32] X.J. Guo, W. Du, X. Wang, Z.F. Yang, Degradation and structure change of humic acids corresponding to water decline in Zoige peatland, Qinghai-Tibet Plateau, Sci. Total Environ. 445-446 (2013) 231-236.

[33] M.B. Heeb, J. Criquet, S.G. Zimmermann-Steffens, U.V. Gunten, Oxidative treatment of bromide-containing waters: formation of bromine and its reactions with inorganic and organic compounds - a critical review, Water Res. 48 (2014) $15-42$.

[34] H.Y.Zhai, X.R. Zhang, Formation and decomposition of new and unknown polar brominated disinfection byproducts during chlorination, Environ. Sci. Technol. 45 (2011) 2194-2201.

[35] Y. Pan, X.R. Zhang, Four groups of new aromatic halogenated disinfection byproducts:effect of bromide concentration on their formation and speciation in chlorinated drinking water, Environ. Sci. Technol. 47 (2013) 1265-1273.

[36] H. Zhao, H.J. Liu, C.Z. Hu, J.H. Qu, Effect of aluminum speciation and structure characterization on preferential removal of disinfection byproduct precursors by aluminum hydroxide coagulation, Environ. Sci. Technol. 43 (2009) 5067-5072. 